Orbis Tertius, vol. XXVI, $n^{\circ}$ 33, e190, mayo-octubre 2021. ISSN 1851-7811

Universidad Nacional de La Plata

Facultad de Humanidades y Ciencias de la Educación

Centro de Estudios de Teoría y Crítica Literaria

\title{
Escritura, política y masividad: Contra y la Revista Multicolor de los Sábados
}

Writing, politics and massiveness: Contra and the Revista Multicolor de los Sábados

María de los Ángeles Mascioto

mariamascioto@gmail.com

Instituto de investigación en Humanidades y Ciencias

Sociales (Universidad Nacional de La Plata-

CONICET), Argentina

Recepción: 14 Abril 2020

Aprobación: 28 Agosto 2020

Publicación: 03 Mayo 2021

Cita sugerida: Mascioto, M. de los A. (2021).

Escritura, política y masividad: Contra y la Revista Multicolor de los Sábados. Orbis Tertius, 26(33),

e190. https://doi.org/10.24215/18517811e190

\begin{abstract}
Resumen: Este artículo se propone analizar las reutilizaciones y porosidades entre vanguardia política e industria cultural en la circulación de escritores, géneros y modalidades de escritura del diario Crítica a la revista Contra y de Contra a la Revista Multicolor de los Sábados con el fin deidentificar tanto las claras diferencias entre el diario masivo, la revista de González Tuñón y el suplemento, como la permeabilidad existente entre ellos. Por un lado, la función social del arte sobre la que los escritores debatían en publicaciones de izquierda entra en tensión con algunas de las aspiraciones comerciales de la empresa periodística. Por otro, las producciones literarias trabajaron con tópicos, imágenes y temáticas provenientes tanto de la industria cultural como de la cultura de izquierda.
\end{abstract}

Palabras clave: Literatura argentina, Industria cultural, Vanguardia política, Publicaciones periódicas.

\begin{abstract}
This article analyzes the relationships between political avant-garde and cultural industry focusing in the circulation of writers, genres and writing modalities among the Argentine newspaper Critica, the review Contra and Critica's literary supplement, Revista Multicolor de los Sábados, in order to identify both the differences among massive newspaper, Gonzalez Tuñon's review, and supplement, as well as the permeability among them. On the one hand, the social function of art about which writers debated in leftist publications created tensions against journalistic commercial aspirations. On the other hand, literary productions worked with topics, images and themes from both cultural industry and left-wing culture.
\end{abstract}

Keywords: Argentine Literature, Cultural Industry, Political Avant Garde, Periodical Publications.

En 1934, el escritor Raúl González Tuñón incluyó en su libro El otro lado de la estrella el ensayo titulado "Los escritores argentinos y la realidad" (1934), en el que se advierte un socavamiento de la antigua pretensión de autonomía, producto de la reflexión en torno a la doble funcionalidad que pasaron a tener sus textos en tanto intervención política y literaria (Alle, 2017). Es posible advertir un viraje similar en la poética de otros escritores como Ricardo Setaro, Carlos Moog y Pablo Rojas Paz, motivado e impulsado principalmente por su circulación no sólo en proyectos revisteriles vinculados con la vanguardia política ${ }^{1}$ como Contra. La revista de los francotiradores, sino y especialmente, en un medio de la industria cultural 
como la Revista Multicolor de los Sábados (1933-1934), suplemento ilustrado de literatura del diario Critica dirigido por Jorge Luis Borges y Ulyses Petit de Murat que dio difusión a sus propuestas literarias. Este aspecto aún no analizado permite identificar nuevos sentidos en la obra de estos autores en los que se evidencian estrechas relaciones entre experimentación poética, militancia política y medios masivos.

Bajo la dirección de Raúl González Tuñón, Contra salió a la calle en abril de 1933 y publicó cinco números mensuales hasta septiembre de ese mismo año. ${ }^{2}$ Entre las publicaciones periódicas de izquierda, ésta ha sido considerada como uno de los espacios más propicios para analizar el clima de confrontación del período (Viñas, 2005; Sarlo, 2007). La revista se enfocaba en el planteo y proposición de nuevos modos de conceptualizar y presentar el compromiso de los intelectuales (escritores y artistas) con la causa revolucionaria.

El diario Crítica, que desde mediados de la década de 1920 había mantenido una relación conflictiva con una de las principales publicaciones periódicas de la vanguardia política argentina -la revista Claridad (1926-1941), dirigida por Antonio Zamora-, mantuvo con Contra un vínculo completamente diferente, signado por influencias dinámicas, reutilizaciones y adaptaciones de formatos. ${ }^{3}$ Son estas reutilizaciones y relaciones las que conformarán el material de análisis del presente artículo.

A partir de 1932, después del levantamiento de la proscripción y el regreso de Natalio Botana -su director- a Argentina, Crítica iniciaba una nueva época en la que se constituía como un actor político a la vez que acrecentaba la publicación de contenido fruitivo. Testimonio de esta particular combinación fue su contratapa, titulada "La diaria voz de Crítica", un espacio abierto a distintas opiniones expresadas tanto en columnas a cargo de artistas vinculados con emprendimientos político-culturales provenientes de los sectores de la izquierda argentina como en viñetas orientadas al entretenimiento, tales como recuadros en los que se interpretaban las líneas de las manos de personajes reconocidos del espectáculo o la cultura, o los dedicados a las palabras cruzadas, además de columnas misceláneas - "Parece mentira”, de Raúl González Tuñón, conformada por pequeñas notas en las que se comentaban acontecimientos vinculados con las esferas política, artística y literaria nacional- y una sección de variedades ilustradas - "Visto y oído", a cargo del dibujante Parpagnoli. ${ }^{4}$

$\mathrm{Al}$ mismo tiempo, en las páginas de Contra colaboraron algunos de los escritores que integraban el staff de redacción del diario, entre los cuales se encontraban los hermanos González Tuñón, Ricardo Setaro, Pablo Rojas Paz, Ulyses Petit de Murat, Demetrio Zadán, Cayetano Cordova Iturburu, José Gabriel y José González Carbalho. Varios de ellos se alistaron entre las voces que dejaban atrás las disputas locales entre el periódico Martín Fierro - principal órgano de la vanguardia estética de los años veinte-y las revistas que dirigió Antonio Zamora, a la vez que expandían su mirada, ahora humanista, hacia las preocupaciones que aquejaban al ámbito intelectual y político internacional entre 1933 y 1934 (Mascioto, 2019a , pp. 73-74). Si en el altercado entre Crítica y Claridad se podía percibir una disputa por la representación popular y por la influencia sobre los lectores (Rogers, 2011), la relación entre el diario masivo y Contra fue de complementariedad. ${ }^{5}$

Fue en la Revista Multicolor donde se incorporó a los escritores y artistas de Contra inmediatamente después de su cierre por cuestiones políticas. Con la creación de este nuevo espacio, el diario dejó de publicar su sección de opinión "La diaria voz de Crítica" y reorientó la producción de dichos escritores y artistas especialmente hacia el entretenimiento. Así, por ejemplo, en las contribuciones de González Tuñón para el suplemento, la escritura de misceláneas políticas como las de "Parece mentira" -columna del diario que luego se trasladó a Contra - cambia por la de textos narrativos orientados a la fruición en los que se contaban historias divertidas sobre personajes que circulaban por la ciudad, como los que aparecieron en la sección "El otro lado de la estrella"6 de la Revista Multicolor de los Sábados (Mascioto, 2012 y 2014).

Analizar los vínculos complejos entre vanguardia política e industria cultural en la circulación de escritores, géneros y modalidades de escritura de Crítica a Contra y de Contra a la Revista Multicolor de los Sábados 
permite identificar tanto las claras diferencias entre el diario, la revista de González Tuñón y el suplemento, como la permeabilidad existente entre ellos. La mirada sobre la función social del arte, que estos escritores debatían en otros espacios entraba en tensión con algunas de las aspiraciones comerciales de la empresa periodística. ${ }^{7}$ Las producciones literarias trabajaron con tópicos, imágenes y temáticas provenientes tanto de la industria cultural como de la cultura de izquierda. Estas reutilizaciones de ninguna manera fueron una mera copia de lo realizado en esos distintos espacios sino que generaron una zona de porosidades entre la literatura y las particularidades del medio, como se observará especialmente en el caso de los cuentos publicados por Carlos Moog en la Revista Multicolor.

\section{De Crítica a Contra: Poesía de prensa}

Contra retomó la auto-identificación como espacio de opinión y debate que caracterizaba al diario y, particularmente, a su página de editoriales "La diaria voz de Crítica". En los cinco números que publicó, la revista implementó una retórica visual cercana a esta contratapa del periódico en la que textos humorísticos y artículos de reflexión política se ordenaban en el mismo espacio de la página. Asimismo, intentó retomar el predominio visual de ésta, dentro de las limitaciones de impresión que podía tener un emprendimiento de este tipo en relación con los adelantos de las prensas rotativas.

Los escritores de Contra trabajaron de manera compleja con el discurso periodístico, al que imitaban, glosaban y comentaban. Fue la experimentación sobre el discurso de la prensa la que les permitió producir textos en los que la militancia política se conjugaba con la experimentación estética, adelantando una modalidad de escritura que luego sería ampliamente practicada en la Revista Multicolor.

De este modo, los poemas de Raúl González Tuñón publicados en Contra - "El poema internacional" ( ${ }^{\circ}$ 2, p.13), "Los nueve negros de Scottsboro" ( $\mathrm{n}^{\circ} 2$, p.13) y "Las brigadas de choque" ( $\mathrm{n}^{\circ} 4$, pp. 8-9) - retomaban las noticias, y las reutilizaban para convertirlas en poesía. Inspirado en un suceso internacional difundido en la prensa, "Los nueve negros de Scottsboro" poematizaba la detención de nueve jóvenes acusados de violar a dos chicas blancas en Alabama, Estados Unidos, y condenados a la silla eléctrica. "El poema internacional" copiaba el discurso periodístico construyendo cada verso a partir del uso de frases impersonales que imitaban los titulares sensacionalistas del diario: "Japón envía un ultimátum a la China. /Henry Pu-Yi tiene sangre de pescado /-tiene sangre fría el Emperador de Manchukuo-“ (Contra, n²:13).

Este tipo de experimentación supuso no sólo la incorporación de las temáticas y preocupaciones de las notas internacionales sino también la conjunción entre frases nominales que imitaban los titulares, o frases entre guiones que añadían puntos de vista. Estas reutilizaciones generaban un contrapunto de información y comentario que ponía a la vista las porosidades entre prensa y literatura. La literatura ponía en juego poéticas periodísticas ${ }^{8}$ y al mismo tiempo devenía espacio desde donde discutir los acontecimientos locales y extranjeros. El debate, la inclusión de "todas las opiniones", se extendía, de este modo, desde los artículos políticos al interior de la producción poemática. En "El poema internacional" se incluyeron, además, voces diversas, algunas más impersonales como las que se citan en el ejemplo, otras más exclamativas que parecieran gritar desde el papel -como sucedía cuando se explicitaba en el poema que los afiches de las calles "gritaban al mundo"-, otras que comentaban los acontecimientos.

Del mismo modo, la relación entre prensa y literatura se hacía evidente en la parte VI de "Las brigadas de choque" cuando el yo lírico se presentaba como un "devorador de noticias", tras lo cual el poema se estructuraba a partir de recursos como la nominalización o el uso de la cita indirecta con signos de exclamación, implementados en la prensa, en contraste con los versos exclamativos:

400 obreros sepultados en un túnel [...]

Se asegura que Blucher es un genio militar y organizador de gran estilo

¡Marchan sobre el mundo los soldados rojos!

¿Queremos la repartición de la tierra! ( $\left.n^{\circ} 4, p .8\right)$. 
Los poemas de Raúl González Tuñón en Contra retomaban el discurso de la prensa a la vez que construían voces disímiles desde donde se intervenía: un yo lírico con rasgos performáticos opinaba, cuestionaba y proponía. Este trabajo de experimentación con los procedimientos propios del diario fue un antecedente inmediato de los cruces y reescrituras implementados en numerosos textos que pocos meses después aparecieron en la Revista Multicolor, en la que los escritores vinculados con la vanguardia política adoptaron una posición militante desde su propia producción literaria, al mismo tiempo que se adaptaban a -y se valían de- los condicionamientos del medio. ${ }^{9}$

\section{Entre Contra y Crítica: La(s) FUnción(es) DeL ARTe}

Desde los primeros años de 1930, una parte de los debates literarios comenzó a girar en torno a la polémica entre "arte puro" y arte al servicio de la revolución. La Revista Multicolor reutilizó y resignificó algunos de los aportes de esta discusión respondiendo, ante todo, a la lógica del beneficio económico dominante en el diario. Esta polémica, que tuvo sus primeras manifestaciones en la respuesta de Carlos Moog a Leónidas Barletta en 1932 sobre las relaciones entre el arte y el ejercicio político, se radicalizó con la llegada de David Alfaro Siqueiros a Argentina y principalmente a partir de la cancelación de la tercera conferencia que daría en la asociación Amigos del Arte. ${ }^{10}$

A partir de su tercer número, la revista de González Tunón hizo explícita su antipatía hacia Victoria Ocampo por su filiación estrecha con Amigos del Arte y el hecho de haber avalado la decisión de la asociación respecto de la obra de Siqueiros - no tanto como directora de la revista Sur que, desde sus inicios en enero de 1931, ganaba relevancia en mundo literario local.

El discurso satírico con respecto a Sur y a su directora, presente no sólo en las notas misceláneas de Contra sino también en los artículos que el mismo Siqueiros publicaba en Crítica, estuvo siempre acompañado por la mención a los "Enemigos del Arte", expresión con la que diario y revista denominaron a aquella agrupación. El accionar de ésta última generó un debate que recogió la encuesta que Contra lanzó entre su tercer y cuarto números, en torno a uno de los ejes más fuertes del conflicto Siqueiros-Amigos del Arte, cuyo título fue "Arte, Arte Puro, Arte propaganda... ¿El arte debe estar al servicio del problema social?”. La presentación en las páginas de la revista no ofreció más que la pregunta, y careció de una introducción en la que se explicaran los motivos que habían llevado a su planteo o la elección de las voces que intervinieron en el debate. La encuesta contó con diversas opiniones de escritores provenientes de la vanguardia estética así como de la vanguardia política (Nydia Lamarque, Luis Waissman, Córdova Iturburu de un lado, Jorge Luis Borges y Oliverio Girondo del otro). En las respuestas se puede ver que los términos de la polémica no eran todavía claros para los seis participantes, quienes encontraron expresiones muy diferentes para abordarla -Nydia Lamarque pensaba la discusión en términos de una oposición entre el arte que "refleja la realidad social" y el "esteticismo puro" al que se consideraba parte de la "decadencia mental" de la clase alta y al que vinculaba con el "arte burgués"; Borges consideraba el debate a partir de términos como "arte al servicio de la política", "arte social” (binomio que consideraba un sinsentido) y "Arte por el Arte"; Luis Waismann se refería al "arte al servicio del proletariado”, Girondo oponía un “arte puro” a otro “de carne y hueso”. La explicación de algunos términos en los que la revista había formulado esta encuesta recién se daba a conocer en la intervención de Cayetano Córdova Iturburu que, más que responder a la pregunta, criticó el punto de vista de Borges. ${ }^{11}$

Critica retomó en sus páginas este debate sobre la función del arte mediante la publicación de notas sobre David Alfaro Siqueiros y la difusión de sus propuestas; en su suplemento, la Revista Multicolor, en cambio, se anuló toda discusión para sacar provecho de la presencia de distintos escritores, temáticas y estilos que compartían el espacio impreso. Desde la portada del primer número, ésta se apropió estratégicamente del título de la recientemente desaparecida Contra, al titular una ilustración de David Alfaro Siqueiros de tamaño 
afiche publicado en la portada de ese primer número con el título de "Contra la corriente", ${ }^{12}$ propiciando en los lectores de las publicaciones periódicas de izquierda -ya acostumbrados a las tapas que reproducían grabados o murales- un efecto de identificación parcial de una publicación con la otra (Mascioto, $2014 \mathrm{y}$ 2018). Quienes compraban el diario podían asociar el personaje que remaba con Siqueiros, como el artista que iba contra la marea; o con la Revista Multicolor, como el suplemento de un diario que iba "en contra" de los "Enemigos del Arte", en apoyo al mexicano. Esta reutilización marcada por el contexto de enunciación en la Revista Multicolor y por el contexto del debate ya citado, y que implicaba una re-significación, se daba también con la inclusión de autores con distintas miradas políticas y estéticas que en otros espacios estaban discutiendo sobre las intervenciones del muralista mexicano.

Como se intentará demostrar en el siguiente apartado, como parte de la industria cultural, el suplemento escenificaba y se componía a partir de una lógica de integración (Rogers, 1998), retomando "todas las voces" de Contra y dándoles una nueva significación mediante la inclusión de los colaboradores en un espacio en el que se articularon diversas propuestas estéticas. La Revista Multicolor apostaba por "la mejor literatura"13 a la que identificaba con la producción de los escritores jóvenes que habían circulado recientemente por revistas orientadas a la vanguardia estética, tales como Martín Fierro, por espacios de la vanguardia política, como Contra y por el mismo diario Crítica.

\section{De Contra a la Revista Multicolor: compromiso, Fruición y eXPerimentación}

En la Revista Multicolor, la seriedad del compromiso político de los artistas interactuaba con el carácter eminentemente fruitivo del suplemento, que incidió en parte en las producciones literarias que se publicaron en sus páginas. Mientras las perspectivas encontradas en torno al debate por la función del arte excedían las páginas de Contra y se expandían, incluso, a "La diaria voz de Crítica", ${ }^{14}$ en el suplemento los escritores no publicaron artículos sobre esta temática sino relatos breves. Asimismo, la ficción predominó sobre el discurso crítico. La producción literaria se encontraba en este medio determinada por ciertas condiciones que dieron relevancia al entretenimiento. Los escritos que incluían temáticas sociales o una clara voluntad de denuncia, compartían el espacio de publicación con textos muy diversos. Al mismo tiempo, como ocurría en Contra, la literatura fue un espacio desde donde se evidenciaron modos de intervenir en los debates políticos.

El predominio de la ficción por sobre la crítica literaria y cultural, así como el desarrollo de la visualidad como la implementación del color y una diagramación que privilegiaba la presencia de dibujos de gran tamaño, entre otros aspectos, convirtieron a la publicación dirigida por Jorge Luis Borges y Ulyses Petit de Murat en un espacio especialmente orientado hacia la fruición (Mascioto, 2014). Al integrar a los escritores que habían participado de Contra -incluso a aquellas voces disidentes como la de Carlos Moog-, adelantamos, la Revista Multicolor metabolizaba sus textos y finalidades promoviendo el reemplazo no exento de tensiones de la escritura ensayística por la ficcional y por un género literario en particular: el cuento. Esto no impidió que algunos de los textos ficcionales que escritores de izquierda como Raúl González Tuñón, Carlos Moog, Ricardo Setaro y Pablo Rojas Paz publicaron en la Revista Multicolor experimentaran sobre las modalidades de escritura de un arte comprometido.

Un caso en el que se pueden ver estas temáticas es en los cuentos que Carlos Moog publicó en el suplemento. ${ }^{15}$ Este escritor afiliado al Partido Comunista Argentino y defensor de la táctica de "clase contra clase" propuesta por la Internacional Comunista en 1928, había exigido desde Contra un mayor compromiso de los intelectuales con la causa revolucionaria. Poco tiempo antes, había polemizado con varios intelectuales de la época sobre este tema, entre ellos, Leónidas Barletta y Pedro Juan Vignale. Al contratar a este autor ligado a la vanguardia política, el suplemento del diario masivo impuso a su escritura algunas particularidades y ritmos propios del medio. 
Simultáneamente a su participación en la Revista Multicolor, Moog escribía artículos y cuentos en Claridad, publicación en la que proponía la implementación de modalidades y temáticas escriturarias vinculadas con las preceptivas del Partido Comunista Argentino, a la vez que reflexionaba sobre la función del intelectual, de los proyectos revisteriles que le daban voz y, fundamentalmente, sobre los espacios de circulación de la literatura de izquierda. En 1932, cuando Leónidas Barletta defendía un arte desligado de los condicionamientos del ejercicio político en el artículo "El Arte y nuestras ideas sociales", publicado en la revista Metrópolis -que él mismo dirigió entre 1931 y 1932-, Carlos Moog le contestaba en una nota con el mismo título desde Actualidad. Económica-política-social.Publicación Ilustrada, dirigida por Elías Castelnuovo. Allí señalaba que, en los tiempos que corrían, el intelectual o el artista se encontraban en una encrucijada cuyas opciones eran claras e irreconciliables: "solo existen dos caminos a seguir: o están con el proletariado o están con la burguesía” (1932, pp. 40-41).

$\mathrm{Al}$ año siguiente, en la primera entrega de "Contra CONTRA", Moog cuestionaría las "desviaciones ideológicas" de Raúl González Tuñón como director de la revista y el "eclecticismo confusionista” de la publicación, que le impedía discernir con claridad desde qué ángulo se debían enfocar "los sistemas”, las teorías y las ideas. Al poco tiempo, desde la columna "Autores y libros" del diario El Mundo, Pedro Juan Vignale respondió a la primera parte de "Contra CONTRA" proponiendo que: "la revolución estética debería hacerse dentro de los límites de la estética, y que toda revolución social se hace con bombas. Y nada de literatura. Nada de obreros enfermos de simbolismos, de cuáqueros, de poemas onomatopéyicos: cada cosa en su plano [...]" (1933, p. 6). Moog cuestionó esta postura en la segunda entrega de "Contra CONTRA" y prometió "desmenuzar" sus afirmaciones en el siguiente número de la revista, que no logró ver la luz. En las discusiones con Barletta y Vignale aparecía incipientemente la polémica entre arte por el arte, arte comprometido y una novedosa preocupación de los escritores por una tercera arista del problema conformada por el arte para el público masivo, así como un cuestionamiento explícito a la publicación y difusión de la literatura en empresas comerciales. ${ }^{16}$ En las dos entregas de su artículo para Contra, Moog defendía una actitud anti-burguesa que debería abarcar todas las acciones de los intelectuales.

Desde estas intervenciones a la participación en la Revista Multicolor no había pasado más que un mes, cuando el suplemento publicó su primer relato, "El infeliz Isaías", el sábado 2 de septiembre de 1933. Este militante orgánico del Partido Comunista Argentino que en otros espacios había cuestionado la participación de escritores de izquierda en empresas masivas, colaboró con un total de cuatro textos en el suplemento de Critica, dos publicados en 1933 y dos en 1934. En ellos pueden observarse, por un lado, las tensiones entre los intereses de la prensa y los de los escritores de izquierda; y por otro, la radicalización de una perspectiva ideológica (que iba desde la defensa del proletariado en los primeros dos cuentos a la promoción de una perspectiva anti-imperialista y antifeudal en los dos últimos) así como una utilización del medio masivo como forma de hacer llegar sus ideas a un público ampliado. Estos dos últimos aspectos pueden observarse ya en el artículo escrito en la revista Claridad, titulado "Arte y revolución en América Latina” (enero de 1934). Allí el escritor hacía uso de los medios periodísticos para difundir su producción literaria y darle un alcance masivo, a la vez que experimentaba con el discurso de la prensa para construir sus textos ficcionales.

La utilización de un medio masivo para difundir su arte distanciaba a Moog de sus planteamientos en Actualidad (1932) y Contra (1933). La lucha frente a la burguesía entraba ahora en tensión con la colaboración en el suplemento de un diario que apoyaba a las grandes empresas. Al igual que otros autores que habían participado de Contra y ahora colaboraban con la Revista Multicolor, Moog escribió para el suplemento relatos breves en los que entraban en relación el tratamiento realista de cuestiones que preocupaban a los sectores intelectuales de la izquierda -tales como los derechos del proletariado y la desocupación- con el carácter fruitivo del diario. Estas tensiones se pueden ver en su propia escritura, dado que los dos primeros cuentos que publicó en el suplemento, "El infeliz Isaías" y "Hospedaje por cuenta del Estado", se acercaban más a los temas del diario (preocupado también por aspectos sociales de la vida 
del pueblo) que a las problemáticas planteadas por la Internacional Comunista, mientras en los dos que le siguieron se retomaron aspectos formulados en "Arte y revolución en América Latina” (Claridad, 1934).

La publicación de estos cuentos en un medio masivo y la adopción de temáticas y recursos característicos del diario permite observar la adaptación de un escritor de ideología antiburguesa y las contradicciones de su discurso. "El infeliz Isaías" ( ${ }^{\circ}$ 4, 2 de septiembre de 1933) cuenta la historia de un hombre de pueblo que se muda a la ciudad y se encuentra allí con un vecino de su lugar de origen que había sido testigo y partícipe de una pelea en la que casi lo matan. El título podría hacer referencia a cualquiera de los personajes que deambulaban por la ciudad y llegaban a la redacción del diario a contar su historia, y la trama descubría una anécdota en la que predominaban las peleas, la sangre y el tono confesional que lo aproximaban a los reportajes de Crítica. Por su parte, "Hospedaje por cuenta del Estado" ( ${ }^{\circ} 12,28$ de octubre de 1933) contaba en primera persona la historia de un preso al que le anunciaban que iba a ser liberado de la cárcel. Entre sus dilemas, antes de salir, cobraban protagonismo las preguntas acerca de qué lugar podría conseguir para dormir el día en que recobrara la libertad y quién le daría trabajo a alguien en su condición. Como en el caso anterior, en éste se volvía a una de las principales características de los reportajes de Crítica: contar historias de la prisión. ${ }^{17}$

Los dos relatos posteriores, publicados ya en 1934, tuvieron una perspectiva bastante diferente y se aproximaron más a los postulados que Moog había expuesto a comienzos de ese mismo año en Claridad. En este caso, no habría solamente una adopción de temáticas del diario sino que el autor propondría desde los mismos textos ficcionales cuestiones más cercanas a las que pregonaba en sus artículos teóricos. La particularidad de estos dos últimos cuentos publicados en la Revista Multicolor, titulados "El fracaso del odio" ( $n^{\circ} 25,27$ de enero de 1934) y "El último hachazo" ( $\mathrm{n}^{\circ} 36,14$ de abril de 1934), consiste en que, sin abandonar sus ideas, el escritor elaboró un tipo de narración que se apropiaba de la voz del obrero, representada ampliamente en el cuerpo de un diario que desde sus inicios se había identificado como el portavoz de los trabajadores.

Esta nueva propuesta coincidía con las ideas expresadas en "Arte y revolución en América Latina"18 de producir una literatura destinada a quienes "no poseen la conciencia de la clase obrera", que pudiera "llegar directamente hacia esa masa" y que planteara "sus propios problemas. ${ }^{19}$ En el apartado "América Latina no es Europa” de este artículo, Moog desarrollaba su propuesta, explicitando además la singularidad de Latinoamérica: "Aquí se plantean problemas y necesidades distintas [a las de Europa] y, en consecuencia, la obra debe ser otra" (1934, p. 24). Luego de identificar la "enorme masa campesina, a la que se descuida totalmente como elemento receptor de un arte que se ajuste a sus características” (p. 24), reconocía a las "grandes capas de indígenas, completamente sojuzgados por los grupos feudal-burgueses de nuestros países latino-americanos (sic.)” (p. 24). En coincidencia con esta crítica, el espacio en que ubicaba a los personajes -obreros- cambiaba en los cuentos de 1934 de la ciudad de Buenos Aires al interior de Argentina e incluso de otros países de América del Sur. Ya no se trataba solamente de trabajar en las usinas o en el puerto, ahora se mencionaban las salitreras, los yerbales, las minas, los cafetales, los cauchales, escenarios por los que fueron circulando los protagonistas de "El último hachazo", relato en el que el narrador en primera persona le detallaba a un muchacho cómo había muerto su hermano -amigo y compañero de trabajo-, siendo hachero y después de haber sufrido todo tipo de explotaciones laborales, también enumeradas en la historia:

“[...] ya habíamos estado [...] en las salitreras de Chile, en los yerbales de Misiones, en los ingenios de Tucumán y Jujuy, en las minas de estaño de Bolivia, en los cafetales de Brasil, en los cauchales de Colombia, en las estancias de la Patagonia y en mil lugares infernales más. Sin embargo, el trabajo de hacheros nos volteó, matando a tu hermano (1934, p. 7).

El cuento retomaba la problemática explotación del quebracho en Chaco, que había sido noticia en el diario varios años antes cuando la compañía La Forestal, conformada en parte por capitales ingleses se expandió en una extensión aproximada de 1.760 .000 hectáreas entre las provincias de Santa Fe y Chaco, ofreciendo condiciones desfavorables de trabajo y un salario excesivamente bajo. De la misma manera, en otras zonas del interior las plantaciones de yerbales y los ingenios azucareros incorporaban mano de 
obra precarizada, entre la que se contaba la población indígena (Cattaruzza, 2012, pp. 95-100). Estas problemáticas sociales se tematizaron también en "El fracaso del odio", cuento en el que una trabajadora discutía con quien iba a ser el "salvador" de los obreros que trabajaban en los ingenios de Salta, un hombre que los había instigado a sublevarse y cuando llegó el momento huyó. El espacio de trabajo era en este cuento un lugar de opresión ubicado en un "pueblecito distante" del norte argentino: "A lo lejos, herméticos y hostiles como cárceles, los edificios del ingenio apresan en su interior una parte de los indígenas dedicados a la penosa faena de trabajar la caña” (1934, p. 7).

En los relatos se tematizaba, así, una parte de la propuesta de Moog en Claridad, en relación con las posibilidades de una revolución en el continente americano que, según el autor, debía ser agraria y anti-imperialista, lo cual significaba: "la revolución de todas las masas explotadas y oprimidas -obreros, campesinos, negros, indígenas, pequeñas burguesías, estudiantes pobres, etc.-"(p. 25); el objetivo de la revolución era la destrucción de aquellos a quienes se consideraba enemigos principales de los explotados: la dominación imperialista y la superioridad de los grandes terratenientes sobre la tierra. Los imperativos de luchar contra la burguesía entraban en tensión con la colaboración en el suplemento literario de un diario que, precisamente, vivía de la pauta publicitaria de otras empresas, muchas de ellas explotadoras de trabajadores, como la Standard Oil, denunciada por Ricardo Setaro (1936). ${ }^{20}$

Estas tensiones no sólo eran ideológicas sino también escriturarias, dado que los cuentos de Moog publicados en 1934, además de ser los más próximos a la perspectiva política del autor, fueron los que mayor cantidad de detalles sensacionalistas incluyeron. En "El fracaso del odio", describía la represión a los indígenas utilizando imágenes truculentas. Del mismo modo, en "El último hachazo", el sensacionalismo predomina desde los primeros párrafos para referir a la descripción del trabajo y de los capataces, a la transformación del hachero tras varias horas de labor, que ocasionaba una mutación tal que parecía convertirlo en una especie de monstruo. Hacia el final del cuento, el narrador no escatimaba descripciones naturalistas de la muerte del personaje principal:

Al levantar el hacha, algo crujió fuertemente dentro de Arturo. Fue como el rasgar de un tejido de seda. Una cosa aguda, rápida, chirriante. Con el hacha cayó una tremenda bocanada de sangre. Luego otro chorro inmenso le vistió el cuerpo de rojo. Se tambaleó y cayó, mientras la sangre, como un río sin fin, manaba a borbotones de su boca y de sus narices (1934, p. 7).

Algo similar sucedía con "el fracaso del odio", en el que la descripción de los violentos castigos que sufrían los obreros tras la sublevación iba in crescendo desde el comienzo hasta el fin del levantamiento y la represión a los indígenas.

El detalle descriptivo del sufrimiento humano a causa de la explotación y la represión que presentaron estos cuentos contrastaba con el material gráfico que se eligió para ilustrarlos. En la imagen central de "El último hachazo", si bien se representa a un personaje robusto levantando un hacha en posición de cortar un árbol, nada parecería indicar que iría a desfallecer en tal trabajo. De una manera similar, las ilustraciones de "El fracaso del odio" no dan indicios de la represión a los obreros; la imagen central los muestra caminando con las cabezas inclinadas, en una representación que se contrapone a la de la iconografía socialista de la época, enfocada en el trabajador fabril en lucha. Las imágenes que acompañan este cuento creaban un imaginario visual alejado del puerto y de la ciudad e insertaban el mundo del trabajo en el ambiente rural. La relevancia visual que tienen los árboles, motivo que se repite en dos de las ilustraciones de ambos cuentos, desvía el foco de atención del contenido social central del texto y lo ponen en relación con el carácter fruitivo del suplemento.

Otros colaboradores de Contra como Pablo Rojas Paz también incluyeron en sus textos ficcionales una reflexión sobre los cambios en la conciencia de los trabajadores en el interior de Argentina. En su cuento "Camino de ida y vuelta" publicado en el suplemento, se narraba el modo en que, frente al trabajo de doce horas en los ingenios de Tucumán - provincia natal del autor- se establecía un nuevo ritmo signado por una modernización que implicaba cambios estructurales llegados desde afuera, cambios que implicaban 
también la dimensión social, que el cuento exhibía en los reclamos de trabajadores que aspiraban a ser sindicalizados. Otro caso en el que se observan las tensiones y adaptaciones de los escritores entre Contra y la Revista Multicolor fue el de Ricardo Setaro, colaborador en ambas publicaciones y autor de seis relatos en el suplemento de Crítica. ${ }^{21}$ Algunos de los relatos que Ricardo Setaro publicó en el suplemento trataron sobre preocupaciones políticas y sociales que dialogaban asimismo con los artículos que publicaba en Contra.

Si en la Revista Multicolor predominaba la fruición y tendía a menguar la discusión política, limitando los espacios de opinión a las pequeñas pastillas misceláneas o a las reseñas de libros, la ficción permitía a los escritores denunciar la explotación y el desempleo a la vez que ofrecer su perspectiva ideológica ante los acontecimientos recientes. Una situación tan desesperante como la de un desocupado que se había ahorcado, producto del hambre, publicada en la nota "Dilema del trabajador moderno" de Contra, era la que se describía en el cuento "La obsesión de Rosina", de Setaro (n 23, 13 de enero de 1934), publicado en la Revista Multicolor. Este relato contaba la historia de una muchacha que, como muchos de los lectores que escribían a Crítica, después de un largo tiempo durante el que había buscado trabajo infructuosamente llegaba a su casa, sin un centavo, con dolor de estómago y con las esperanzas desmoronadas, "como se desmorona el prestigio de los políticos cuando llegan al poder" (1934, p. 7), y ante la insinuación de prostituirse que le hacía un estudiante, lo apuñalaba. La preocupación por los personajes que caminaban por la ciudad sin rumbo y sin empleo puede vincularse con una situación propia de una época de crisis política, económica y social, que no aparecía de manera tan explícita en el diario entonces oficialista.

La presencia en los textos ficcionales de Setaro y Moog de protagonistas mujeres que formaban parte de la vida pública y del mundo laboral, tal como se puede leer en "La obsesión de Rosina" del primero y "El fracaso del odio" del segundo, entraban en sintonía con los debates promovidos por publicaciones de izquierda feministas como Vida Femenina (1933-1937) y Mujeres de América (1933-1936). La construcción ficcional de la mujer como obrera, como vagabunda o incluso como criminal se instalaba en estos relatos para competir con la imagen del ser femenino como madre, esposa o actriz, profusamente difundida en los textos e ilustraciones del diario y del suplemento. En sintonía con estas problemáticas en la Revista Multicolor se publicaron notas como "También las mujeres se hacen vagabundas", firmada por Reckless y profusamente ilustrada, en la que se describía la vida en las calles de Nueva York y las diferencias que imponía el género.

\section{CONSIDERACIONES FINALES}

Las influencias y las reutilizaciones de modalidades escriturarias entre Crítica, Contra y la Revista Multicolor ponen en evidencia las adaptaciones y tensiones entre algunos postulados respecto del arte propios de cierta izquierda y la industria cultural, al mismo tiempo que permiten advertir en el suplemento un espacio en el que estos escritores llevaron a cabo algunos de sus objetivos estéticos y políticos.

Aunque con la creación de la Revista Multicolor desaparecía "La diaria voz de Crítica", sección de la contratapa del diario destinada a los artículos de opinión, los escritores de la vanguardia política trabajaron en los textos ficcionales que publicaron en el suplemento cuestiones estrechamente ligadas con las que se habían planteado en ensayos publicados en otros medios, donde se reflexionaba sobre la función del arte, el modo de actuar ante los problemas del proletariado y las formas de hacer llegar la producción literaria a un público masivo.

Si, como señalan Kalifa y Vaillant (2004), los periódicos fueron espacios en los que se construyeron identidades sociales y culturales, en el suplemento de Crítica los escritores vinculados con la vanguardia política convirtieron esas identidades en ficcionales a la vez que problematizaron la vida en las calles, la explotación y la falta de empleo en el ámbito local e internacional, y denunciaban lo que ellos consideraban un "desinterés" por parte del diario. ${ }^{22}$ 


\section{REFERENCIAS}

Alle, M. F. (2017). El tránsito hacia la revolución. Raúl González Tuñón en la primera mitad de los años treinta. El taco en la brea, 4(5), 10-38.

Cattaruzza, A. (2012). Historia de la Argentina, 1916-1955. Buenos Aires: Siglo Veintiuno.

Córdova Iturburu, C. (1933). Arte, Arte Puro, Arte Propaganda....Contra. La revista de los francotiradores, 4, 12.

Gonzalez Tuñón, R. (1933). El poema internacional. Contra. La revista de los francotiradores, 1(2), 13.

Gonzalez Tuñón, R. (1933). Los nueve negros de Scottsboro. Contra. La revista de los francotiradores, 1(2), 13.

Gonzalez Tuñón, R. (1933). Las brigadas de choque. Contra. La revista de los francotiradores, 1(4), 8-9.

Gonzalez Tuñón, R. (1934). Los escritores y la realidad. En El otro lado de la estrella. Buenos Aires/Montevideo: Sociedad Amigos del Libro Rioplatense.

Kalifa, D., Vaillant, A. (2004). Pour une histoire culturelle et littéraire de la presse française au XIXe siècle. Le temps des médias, vol.1 (2), 197-214.

Mascioto, M. A. (2012). Raúl González Tuñón y Jorge Luis Borges en la Revista Multicolor de los Sábados: literatura y periodismo. VIII Congreso Internacional Orbis Tertius "Literaturas compartidas". Universidad Nacional de La Plata.

Mascioto, M. A. (2014). Suplemento de literatura: cultura impresa y ficción en la Revista Multicolor de los Sábados. En V. Delgado et al., directoras. Tramas impresas: Publicaciones periódicas argentinas (XIX-XX). La Plata: Edulp.

Mascioto, M. A. (2018). El pintor que escribe en un muro de papel: David Alfaro Siqueiros en la Revista Multicolor de los Sábados. Catedral Tomada. Revista de crítica literaria latinoamericana, 6(11).

Mascioto, M. A. (2019a). Museo de un género en declive: la revista Poesía, de Pedro Juan Vignale (1933). En: Delgado, V. y Rogers, G. (Eds.). Revistas, archivo y exposición. Publicaciones periódicas argentinas del siglo XX (pp. 73- 92). Colección Colectivo Crítico, Facultad de Humanidades y Ciencias de la Educación, UNLP.

Mascioto, M. A. (2019b). Nuevos modos de escritura en la Revista Multicolor de los Sábados (1933-1934). Tesis de Doctorado en Letras. La Plata: Universidad Nacional de La Plata (mimeo).

Moog, C. (1932). El arte y nuestras ideas sociales. Actualidad. Económica-politica-social. Publicación Ilustrada, 1(3), 3.

Moog, C. (1993). Contra "Contra". Contra. La revista de los francotiradores, 1(3), 12.

Moog, C. (1933). El infeliz Isaías. Revista Multicolor de los Sábados, 7, (2 de septiembre de 1933), 7.

Moog, C. (1933). Hospedaje por cuenta del Estado. Revista Multicolor de los Sábados, 12 (28 de octubre), 2.

Moog, C. (1934). El fracaso del odio. Revista Multicolor de los Sábados, 25 (27 de enero), 6.

Moog, C. (1934). El último hachazo. Revista Multicolor de los Sábados, 36 (14 de abril), 7.

Moog, C. (1934). Arte y revolución en América Latina. Claridad, 12(273), 23-27.

Oliveto, M. (2014). Elproblema de la lengua literaria: Disputas y condiciones de transformación en la Argentina de 1920. Tesis de Doctorado en Letras. La Plata: Universidad Nacional de La Plata.

Rogers, G. (1998). Caras y Caretas: la lógica de la integración. Orbis Tertius, 3(6), 1-10.

Rogers, G. (2011). Claridad y los martinfierristas en Crítica. En Actas del Cuarto Congreso Internacional CELEHIS de Literatura. Mar del Plata: CELEHIS.

Sarlo, B. (2007). Una modernidad periférica: Buenos Aires 1920 y 1930. Buenos Aires: Nueva visión.

Saítta, S. (2005). Polémicas ideológicas, debates literarios en Contra. La revista de los francotradores. Contra, la revista de los francotiradores. Bernal: Universidad Nacional de Quilmes.

Setaro, R. (1934). La obsesión de Rosina. Revista Multicolor de los Sábados, 23 (13 de enero), 7.

Setaro, R. (1936). La vida privada del periodismo. Buenos Aires: Fegrabo.

Vignale, P. J. (1933). Autores y libros. El Mundo, 7 de julio, 6.

Viñas, D. (2005). Cinco entredichos con Raúl González Tuñón. En: AAVV. Por Tuñón. Buenos Aires: Centro Cultural de la Cooperación Floreal Gorini. 
Thérenty, M-E. (2007) La littérature au quotidien. Poétiques journalistiques au XIX Siècle. París: Éditions du Seuil.

\section{Notas}

1 La expresión "vanguardia política" se utiliza en esta investigación para referir a artistas y escritores que consideraron su práctica estética como una forma de activismo político.

2 Una presentación y análisis de las principales características de Contra se encuentra en Saítta (2005).

3 Entre 1926 y 1927 Claridad se había enfrentado al diario, al que cuestionaba haber integrado a su staff escritores vinculados con la vanguardia estética, tales como Horacio Rega Molina, Pablo Rojas Paz, Enrique y Raúl González Tuñón, Conrado Nalé Roxlo, Nicolás Olivari, Carlos de la Púa y Roberto Arlt. Los detalles de esta afrenta han sido analizados por Geraldine Rogers (2011) y Mariano Olivetto (2014).

4 En esta página colaboraron, además, los escritores Pablo Rojas Paz, Raúl González Tuñón, Conrado Nalé Roxlo, entre otros.

5 Esto puede advertirse desde el momento en que salió la revista de Raúl González Tuñón y en la promoción que el diario hacía de esta nueva publicación. Por otro lado, al salir Contra se trasladaba "La diaria voz de Crítica" de la contratapa del periódico al espacio menos destacado de la segunda sección (Mascioto, 2014, p. 209).

6 Las particularidades de los artículos de esta sección y su posterior publicación en el libro homónimo son analizados en Mascioto (2012).

7 Testimonio de estas tensiones es el libro La vida privada del periodismo (1936), de Ricardo Setaro, en el que el escritor mendocino cuestiona la política mercantil de Crítica que lleva al diario a buscar el aumento de tirajes "a cualquier precio": "Para ello Crítica edita varias ediciones diarias; regala suplementos en colores; ofrece páginas enteras de entretenimiento [...].” (Setaro, 1936, p. 69). En su cuestionamiento incluye una cita del mismo Raúl González Tuñón acerca de la libertad de expresión del periódico: "El diario [Crítica] va a todas partes. Avisos de los burgueses al lado de notas sobre la desocupación [...]. Mientras tanto, hay que mantener el ánimo de los redactores. Hay que decirles: 'pueden ustedes escribir con total libertad'. Pero cuidado si esa libertad molesta a la Oficina de Publicidad” (en Setaro, 1936, p. 72).

8 Marie-Ève Thérenty utiliza esta noción ("poétiques journalistiques") para analizar la coincidencia de dos "sistemas discursivos”, el literario y el periodístico, los fenómenos de contaminación, préstamos, intercambios e interacciones entre ambos desde mediados del siglo XIX (2007, p.19)

9 Asimismo, también puede verse esta continuidad y complementariedad entre el diario y la revista en algunos artículos publicados en la sección "La diaria voz de Crítica" y los que aparecieron en Contra, en función del interés por ciertos temas y el posicionamiento de los escritores respecto de ellos. La página de opiniones del diario, no obstante, fue un espacio más moderado que la revista. De manera que si en otro tipo de notas Crítica publicaba imágenes sensacionalistas que convertían al lector en espectador, en "La diaria voz..." se evitan las fotografías y las ilustraciones que no respondían al entretenimiento o a la sátira política. Estas cuestiones son trabajadas en detalle en Mascioto (2019b).

10 Analizamos la polémica que surge a partir de esta cancelación y los vínculos entre vanguardia política e industria cultural en las producciones de David Alfaro Siqueiros para Crítica y su suplemento ilustrado de literatura en Mascioto (2018).

11 En esta respuesta, Córdova Iturburu especifica y orienta la pregunta: "Cuando [a Borges] se le formuló la pregunta ¿Debe estar el arte al servicio de la revolución? Quiso decírsele -y el no pudo dejar de entenderlo- ¿No cree Ud. que esa ideología y ese sentimiento revolucionarios tienen bastante dignidad humana para engendrar un arte? ¿No creen Ud. que ese espíritu universal de revuelta, generador en el sentimiento heroico de la justicia necesaria, asume una dignidad suficiente como para que los artistas desciendan de su pedestal y presten oído al rumor amenazante de marea que sube desde las capas inferiores de la sociedad? ¿No cree Ud. que el mundo ha cambiado, que algo se ha roto para siempre, que algo para siempre ha nacido y que ese algo -sentimiento, idea- puede constituir en muchos corazones una religión nueva, una emoción universal rica de elementos artísticamente utilizables?” (1933, p. 12).

12 Esta obra sólo conserva su nombre en el contexto de la Revista Multicolor de los Sábados. Años después, en 1936, la litografía original fue subastada como "El botero".

13 Tal era el slogan que promocionaba al suplemento, "la mejor literatura para el más amplio público".

14 Un caso particular en este sentido es el de Pablo Rojas Paz. Cuando comenzaron las intervenciones sobre la polémica Siqueiros - Amigos del Arte en Contra, Rojas Paz dejó de colaborar con la revista de los francotiradores. Quizás podamos encontrar una posible explicación en la defensa que el autor tucumano hizo desde una nota editorial en Crítica del mes de agosto a los jóvenes pintores que iban a exponer en el Palais de Glace y que sentían pasión, principalmente, por su arte y no por la política. Rojas Paz admira esta actitud y cuestiona otras: "Ahora muchos pintores creen que es necesario hacer varias cosas a la vez. Hacer política artística, enseñar y, en último caso, pintar. Pintar para no perder la mano”. El pintor, entonces, debería dedicarse a pintar y no a dar cátedra: "parece que en nuestro ambiente no basta con ser pintor, hay que enseñar la pintura que no se ha podido hacer y esto es lo malo, resulta que siempre se aprende el arte para enseñarlo y no 
para aprovecharse artísticamente de él” (p. 33). Este comentario toma un punto de vista con respecto al tema expuesto en la encuesta que realizó Contra sobre la cuestión de si el arte debe estar al servicio del problema social.

15 Otro caso representativo es el de la participación de Raúl González Tuñón en la Revista Multicolor, cfr. Mascioto (2012).

16 La posición de Vignale se reafirma en la creación de su revista Poesía (1933). En la nota de presentación, firmada por él mismo y publicada en las primeras páginas del número 1 de Poesía, Vignale cuestiona a los poetas que: "por querer humanizarse, como si fuera posible dejar de ser humanos, mezclaron ingredientes sociales a su poesía e hicieron política, olvidando que el arte -la poesía-contiene en sí una forma particular de política que lo trasciende" (Vignale, 1933, p. 5).

17 El texto no imita el formato del reportaje aunque algunos elementos como el relato en primera persona de los presos y el detallismo de la descripción que se hace de la prisión los emparentan. Las entrevistas a prisioneros cobran un rol fundamental en el diario e inciden en la escritura del suplemento (Mascioto, 2017)

18 Moog, Carlos. "Arte y revolución en América Latina." Claridad (Buenos Aires) 12, no 273 (Enero 1934), pp. 23-27.

19 Así lo señala Moog en su artículo: "Se necesita un arte anti-imperialista y anti-feudal burgués. Un arte que todas esas masas oprimidas enumeradas, que no son totalmente proletarias, que no poseen la conciencia de clase de la clase obrera, pero que deben cumplir un papel revolucionario, puedan captar y que sea para ellas un valioso elemento de agitación [...]. Un arte revolucionario que llegue directamente hacia esa masa obrera, campesina, indígena, etc., etc., y planteando sus propios problemas, aclarando sus particulares inquietudes y señalándoles el camino único de su emancipación, las ayude a combatir con éxito las influencias reaccionarias, imperialistas, que en el sector artístico se infiltran poderosamente a través de vastos medios de que disponen nuestros contrarios: la radio, el cine, el teatro, el libro, la prensa, etc., etc" (1934, p. 26).

20 La denuncia de Setaro remitía, asimismo, a la postura de apoyo que adoptó el diario hacia esta empresa petrolera estadounidense instaurada en Bolivia y que entró en tensión con la perspectiva antibelicista de González Tuñón, manifestada en las crónicas que publicó como enviado especial a la guerra del Chaco, tituladas "Crítica en el infierno del Chaco" y publicadas diariamente entre el 19 y el 27 de octubre de 1932, posición compartida por otros escritores vinculados con el Partido Comunista.

21 Estos relatos son: "El degollador de fantasmas" ( $\left.n^{\circ} 1\right)$, "El enigma de los ojos en la pared" ( $\left.\mathrm{n}^{\circ} 13\right)$, "La obsesión de

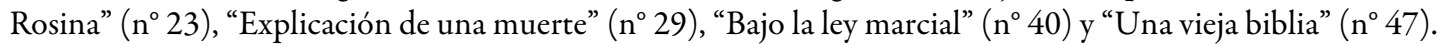

22 Éste último aparecía muchas veces representado en las ficciones como un medio de información pero no de denuncia. 